\title{
Are the Hot IPOs Still Relevant? Evidence from China's Growth Enterprise Market
}

\author{
Lu Yang ${ }^{1}$, Huimin Zhang $^{2}$ and Shigeyuki Hamori ${ }^{3, *}$ \\ ${ }^{1}$ School of Finance, Zhongnan University of Economics and Law, Wuhan 430073, China \\ ${ }^{2}$ Graduate School of Foreign Language and Literature, Wuhan University, Wuhan 430072, China \\ ${ }^{3}$ Faculty of Economics, Kobe University, 2-1, Rokkodai, Nada-Ku, Kobe 657-8501, Japan
}

\begin{abstract}
This paper investigates whether the hot IPO effect persists post-IPO in China's Growth Enterprise Market (GEM) based on the dynamic equicorrelation of trading volume and stock returns. We find that the hot IPO effect ends after two years with the imbalance between demand and supply for GEM stock relieved, which indicates that the rational learning process requires almost two years for most investors. Further, we confirm that returns and volumes are positively correlated at the $1 \%$ significance level. This result indicates that the fundamental analysis may not apply to the GEM because the information content of trading volume is capable of forecasting stock returns.
\end{abstract}

Keywords: Hot IPOs, Dynamic equicorrelation (DECO), Growth Enterprise Market (GEM), China.

\section{INTRODUCTION}

The Growth Enterprise Market (GEM) has played an important role in the economic system that provides small- and medium-sized, high-tech enterprises a platform to raise equity funding, especially during the recent economic transformation in China. The Growth Enterprise Market (GEM) of the fastest growing stock exchange markets in China, and GEM market value have increased dramatically from 160 billion Yuan (US\$ 25.7 billion) in 2009 to 719.9 billion Yuan (US\$ 116.3 billion) in 2013. Before the China GEM opened, most high-tech enterprises chose to finance in Hong Kong or NASDAQ, which does not benefit the economic growth of China. To spur efficient economic growth, the Chinese government implements dozens of policies to prepare for the economic transition. A significant policy is the opening of the GEM, which provides opportunities for the development of high-tech industries in China. The development of the GEM will transform the Chinese economy from the traditional "three-high" industries-high polluting, high energy consuming, and high water consuming-into a high-tech industry economy. The China GEM is now widely considered a hot IPO market (Ibbotson and Jaffe, 1975).

As of 2013, the number of companies listed on the GEM Shenzhen is 355 . However, only 28 companies were listed initially. Therefore, to collect enough data periods, we chose the sample from these 28 companies. All of these companies are small with high

*Address correspondence to this author at the Faculty of Economics, Kobe University, 2-1, Rokkodai, Nada-Ku, Kobe 657-8501, Japan;

Tel: +81-78-803-6832; E-mail: hamori@econ.kobe-u.ac.jp growth potential and find it difficult to satisfy the listing requirements of the Main Board. Their price increases on the day that they list on the Board by approximately $200 \%$. The companies listed on China's Main Board must satisfy a greater number of strict requirements for their initial public offerings (IPOs) than their GEM counterparts for indicators such as profitability, scale, and asset quality. The firms listed on the GEM are considered higher risk than the firms listed on the Main Board. Although both the China Main Board and China's GEM are organized as a pure order-driven market, the trader in the China GEM must satisfy additional requirements to enter the market. Only qualified investors possess a license to enter this market. Therefore, individual investors who comprise a significant portion of capital markets are unlikely to obtain a license to buy stock in this market. For instance, an investor must have three years of investment experience before obtaining this type of license. Both the IPO and market participant requirements differentiate the China GEM to such an extent that these two markets are significantly different. Therefore, GEM stocks are considered hot IPOs or issues because of their scarcity.

Although GEM firms are chased by fund numbers, the continued increases in price cannot be sustained over the long term. This paper investigates how long these stocks will be chased based on the equicorrelation dynamic (DECO) of trading volume and stock returns. The basic assumption behind the dynamic is that the DECO of both trading volume and stock returns will be high during the "hot period," particularly for the DECO of trading volume. If either DECO falls, the hot issue effect will disappear. 
Moreover, because the price of stock is determined by the present value of future dividends, most companies in GEM are still small with few dividends to deliver. Alternatively, the companies that share high P/E ratios reflect the high growth potential of the companies. However, a severe adverse selection problem will be observed in the China GEM because there is limited supervision. The undisclosed information from listed firms creates information asymmetry between the public and firms, which causes the market stock price to deviate from its fundamentals. Because the requirements for entering the market are strict, most investors are considered professional investors. Therefore, the correlation between stock returns and trading volume may be the best indicator to justify fair value of the companies; it is hard to determine the stock price based solely on fundamentals. Further, the stock returns and trading volumes also include the expectations of investors for future company growth; therefore, the correlation between them will reflect the movement of future perspectives of the companies, especially for contemporary China.

This paper focuses on the dynamic equicorrelations between trading volume and stock returns using a DECO-GARCH model ${ }^{1}$ (Engle and Kelly, 2012). Further, this paper addresses the following questions: (1) How long will the hot issue effect persist after an IPO? (2) Is there a strong relationship between trading volume and stock returns in the GEM, and how does this type of relationship evolve with time? (3) Does the market work efficiently or how long does rational learning take to justify the fair value of the stock after IPO?

The remainder of this paper is organized as follows. Section 2 provides an overview of the related literature. Section 3 discusses various copulas to verify dependence structures. Section 4 describes the data and statistical issues. Section 5 provides the empirical results, and Section 6 concludes the study.

\section{LITERATURE REVIEW}

A number of studies have analyzed the hot issue market since lbbotson and Jaffe (1975), who noted that a period with high levels of initial returns tends to coincide with a large volume of IPOs. Subsequently, many studies suggested that rationale is the relationship between high levels of initial returns and

${ }^{1}$ For further applications of the DECO model, please refer to Aboura and Chevallier (2014) and Yilmaz (2015). the large volume IPOs (Ritter, 1984; Brailsford et al., 2000; Lowry, 2003). Further, the relationship between trading volume and stock price changes has attracted attention from the finance community in recent decades. Early studies in this area can be traced to the contribution of Karpoff (1987), who found a positive correlation between absolute price changes and trading volumes. Since then, numerous studies have been documented. For instance, Campbell et al. (1993) provided evidence that the return-volume relationship contributes to solving the identification problem for testing different models.

Two methodologies have addressed the issues during the past two decades. The first is the vector autoregressive (VAR) model and Granger causality tests that investigate the hot/cold issuing cycles in hot IPO markets (Brailsford et al., 2000; Lin et al., 2009; Guo et al., 2010) and dynamic return-volume relationships (Lee and Rui, 2002, Statman et al., 2006, Griffin et al., 2007, and Hutson et al., 2008). The most current methodology is the contribution of Guo et al. (2010), which identified the hot and cold period in the Chinese A-share IPO market based on the MS-VAR model. Chen (2012) found that stock return is capable of predicting trading volume in both bear and bull markets, whereas the trading volume capability to predict stock returns is weaker based on the MS-VAR model.

The second is the GARCH-based model of Engle (1982) and Bollerslev (1986), which examines the dynamic correlation between trading volume and stock returns. Most studies focus on the Mixture of Distributions Hypothesis (MDH), which investigates the relationship of return-volume volatility (Andersen, 1996; $\mathrm{Li}$ and Wu, 2006; and Girard and Biswas, 2007). The latest is the study of Carroll and Kearney (2012), who provide evidence of the MDH for the British stock market based on the GARCH-based tests.

Further, Karpoff (1987) noted that volume is positively correlated with positive price changes and negatively correlated with negative price changes; therefore, its correlation should be positive. Another area can examine this correlation in the extreme case. For instance, Ning and Wirjanto (2009) found that the return-volume dependence is asymmetric in the extreme case using the copula approach from the analysis of six emerging East-Asian equity markets.

In contrast to previous studies, we choose China GEM firms as our object to analyze the hot issue effect 
and the relationship of trading volume and stock returns based on the DECO-GARCH model (Engle and Kelly, 2012). Few studies address the China GEM, and this discussion contributes to the current financial literature in terms of the chosen market and the econometric method applied. Further, we choose nine firms from the established GEM to analyze how long the hot issue effect persists based on a firm's level, which represents a unique approach that no study has adopted. The China economy is experiencing a period of structural transformation. Whether it succeeds will depend on the transformation of its financial markets, especially the GEM, which offers an opportunity to improve the level of the industry as a whole.

\section{ECONOMETRIC METHODOLOGY}

Engle and Kelly (2012) raise a different version of the DCC-MGARCH model, namely, DECO-MGARCH ${ }^{2}$. They assume an average of conditional correlation equal to all pair correlations to simplify the calculations of large-scale correlation matrices. Following the studies of Engle and Kelly (2012), this paper examines the dynamic equicorrelation (DECO) between transaction volume and stock returns by adopting the following two-step approach. In the first step, we estimate the conditional variance of both stock returns and trading volume based on an autoregressive (AR) model for the conditional mean and a GARCH model (Bollerslev, 1986). The AR (k)-GARCH $(p, q)$ specification is expressed as follows:

$r_{t}=C+\sum_{i=1}^{k} A R_{i} r_{t-i}+\varepsilon_{t}, E_{t-1}(\varepsilon t)=0, E_{t}-1\left(\varepsilon_{t}^{2}\right)=\sigma^{2}$

and

$h_{i, t}=\omega_{i}+\alpha_{i} \varepsilon_{i, t-1}^{2}+\beta_{i} h_{i, t-1}$

where $E_{t-1}$ is the conditional information operator based on the information at time $t-1$.

In Eq. (1), the $\operatorname{AR}(k)$ model, indicates that the current movement of a variable $x_{t}$ can be explained by its own past movement $\left(r_{t-1}, r_{t-2}, \ldots\right)$. In this paper, the variable $r_{t}$ is represented by asset returns. In Eq. (2), the persistence of shocks to the conditional variance is given by $\sum_{i-1}^{q} \beta_{i}$.

${ }^{2}$ For the detailed definition of equicorrelation, please refer to Engle and Kelly (2012).
Because the residuals $\varepsilon_{t}$ are skewed and heavy tailed, we assume that the density function of $\varepsilon_{t}$ follow Student's t-distribution ${ }^{3}$ given by:

$f(t)=\frac{\Gamma\left(\frac{v+1}{2}\right)}{\sqrt{v \pi} \Gamma\left(\frac{v}{2}\right)}\left(1+\frac{t^{2}}{v}\right)^{-\frac{v+1}{2}}$

where $v$ is the number of degrees of freedom and $\Gamma$ is the gamma function.

The maximum likelihood method was used to estimate each model. The Schwarz Bayesian information criterion (SBIC) was used to evaluate the AR terms by choosing the smallest values. The LjungBox $Q$ test was applied to examine the residuals of the AR term. According to the SBIC and residual diagnostics, the values of $k, p$, and $q$ range from $k=1$, $2 \ldots, 5 ; p=1,2$; and $q=1,2$, respectively.

In the second step, based on the conditional volatilities from Eq. (2), we calculate the conditional correlations from the conditional covariance matrix:

$H_{t}=E\left[\varepsilon_{t} \varepsilon_{t}^{\prime}\right]=D_{t} R_{t} D_{t}$

where the diagonal matrix $D_{t}$ is the conditional volatilities from Eq. (2).

Therefore, the trend of the generalized DCC model (Engle, 2002) can be specified as

$Q_{t}=\left(\bar{Q}-A^{\prime} \bar{Q} A-B^{\prime} \bar{Q} B\right)+A^{\prime} z_{t-1} z_{t-1}^{\prime} A+B^{\prime} Q_{t-1} B$

where $\bar{Q}$ represents the unconditional correlation matrices of $z_{t}$. Therefore, the conditional correlation matrix $R_{t}$ is derived as

$R_{t}^{D C C}=Q_{t}^{*-1} Q_{t} Q_{t}^{*-1}$

where the diagonal matrix $Q_{t}^{*}=\sqrt{q_{i i, t}}$ contains the square roots of the diagonal elements of $Q_{t}$.

DECO sets $\rho_{t}$ equal to the average pairwise DCC correlation

$R_{t}^{D E C O}=\left(1-\rho_{t}\right) I_{n}+\rho_{t} J_{n \times n}$

${ }^{3}$ The generalized error distribution does not provide robust results according to the properties of data, nor does it generalize to a multivariate process. 
Table 1: Descriptive Statistics of Returns

\begin{tabular}{|c|c|c|c|c|c|c|c|}
\hline & Mean & Median & Std.Dev. & Skewness & Kurtosis & Jarque-Bera & $Q(10)$ \\
\hline LMT & -0.0006 & 0.0008 & 0.0269 & -0.3318 & 4.5631 & $103.69^{* * * *}$ & $16.186^{* *}$ \\
\hline JXML. & -0.0007 & 0.0013 & 0.0342 & -3.1928 & 49.483 & $79162^{* * *}$ & $22.101^{\star \star *}$ \\
\hline EE & 0.0007 & 0.0011 & 0.0317 & -0.0008 & 4.0414 & $38.999^{* * *}$ & $19.647^{* * *}$ \\
\hline $\mathrm{AEH}$ & 0.0006 & 0.0011 & 0.0260 & -0.0212 & 4.4038 & $70.929^{* * *}$ & $14.095^{* *}$ \\
\hline BBP & 0.0001 & 0.0013 & 0.0271 & -0.2503 & 4.5601 & $96.535^{* * * *}$ & $14.538^{* *}$ \\
\hline GDYW & -0.0005 & 0.0033 & 0.0408 & -6.1848 & 110.92 & $42435^{* * *}$ & $18.738^{* * *}$ \\
\hline GAMC & 0.0004 & 0.0009 & 0.0338 & 0.0337 & 4.2055 & $52.422^{* * *}$ & $14.947^{* *}$ \\
\hline BEE & -0.0001 & 0.0011 & 0.0324 & 0.0257 & 4.6091 & $93.209^{* * *}$ & $16.192^{\star * *}$ \\
\hline SRA. & 0.0010 & 0.0018 & 0.0311 & -0.2342 & 4.3140 & $69.980^{* * *}$ & $11.830^{*}$ \\
\hline
\end{tabular}

Notes: LMT, JXML, EE, AEH, BBP, GDYW, GAMC, BEE, and SRA represent Lepu Medical Technology, Jiangsu Xinning Modern Logistics, Eve Energy, Aier Eye Hospital, Beijing Beilu Pharmaceutical, Gansu Da Yu Water-saving, Gifore Agricultural Machinery Chain, Bode Energy Equipment, and Siasun Robot \& Automation, respectively.

${ }^{*},{ }^{* \star}$, and ${ }^{* \star \star}$ indicate significance at the $10 \%, 5 \%$, and $1 \%$ levels, respectively.

and

$\rho_{t}=\frac{2}{n(n-1)} \sum_{i>j} \frac{q_{i, j, t}}{\sqrt{q_{i, i, t} q_{j, j, t}}}$

where $I_{n}$ denotes the $\mathrm{n}$-dimensional identity matrix, $J_{n \times n}$ denotes the $n \times n$ matrix of ones, and $q_{i, j, t}$ is the $i$, jth element of $Q_{t}$. The following restriction conditions are required $a+b<1, a>0, b>0$, where $a=A^{\prime} A$ and $b=B^{\prime} B$. DCC only describes the correlation between assets $i$ and $j$ at time t based on the history of assets $i$ and $j$ alone, while DECO assumes this type of correlation depends on the history of all pairs. The stock prices are linked closely with each other, particularly stocks with the same properties of the enterprises such as high risk and high growth rates. This provides sufficient evidence that the DECO model can provide superior estimation results than DCC. We estimate the DECO model by employing the Gaussian quasi-maximum likelihood method.

\section{DATA}

Our data comprise daily returns and trading volumes of the nine firms ${ }^{4}$ from the first group of listed companies in the China GEM. The models are estimated over the sample period from November 2, 2009, when the China GEM was founded, to October 15,2013 , when the research was completed, providing 863 effective observations for each stock when the

${ }^{4}$ Even though we have the full sample of 28 listed companies, to obtain effective observations we do not use them all because most have substantial trade suspensions for different reasons. Further, because of data properties, the GARCH process is also difficult to capture. days of public holiday and trade suspension are excluded. All data come from DataStream.

Table 1 provides the summary statistics, which detail the returns for each stock. The stock returns are calculated as $R_{t}=\log \left(P_{t} / P_{t-1}\right) \times 100$. Table 2 provides the summary statistics that detail the trading volume for each stock. Outstanding shares may change over time; therefore, to avoid this bias, we use trading volume divided by outstanding shares as a relative indicator. Further, the results of the Jarque-Bera (J-B) test show that the null hypothesis of the normal distribution is rejected in all cases. The results of the Ljung-Box $Q$ statistics demonstrate the existence of serial correlation for each series.

\section{EMPIRICAL FINDINGS}

We use a two-step method to estimate the dynamic equicorrelation for both trading volume and stock returns. In the first step, we estimate the marginal distributions for each series. In the second step, we estimate the DECO based on the standardized residuals from step one. Because of the nonstationarity property of the trading volume, we consider the percentage changes in volume in our empirical analysis: $v_{t}=\log \left(V_{t} / V_{t-1}\right) \times 100$.

\subsection{Marginal Distribution Specifications}

In the first step, we choose the most appropriate specifications for modeling conditional heteroscedasticity according to the usual information criteria, such as the Akaike information criterion (AIC), Schwarz Bayesian information criterion (SBIC), and log likelihood (logLik) statistics by employing univariate GARCH models (Verbeek, 2004). Tables 3 and 4 
Table 2: Descriptive Statistics of Volumes

\begin{tabular}{|c|c|c|c|c|c|c|c|}
\hline & Mean & Median & Std.Dev. & Skewness & Kurtosis & Jarque-Bera & $Q(10)$ \\
\hline \hline LMT & 0.0057 & 0.0038 & 0.0056 & 2.8132 & 14.707 & $6066.5^{* * *}$ & $3075.1^{* * *}$ \\
\hline JXML. & 0.0157 & 0.0108 & 0.0147 & 2.6448 & 12.526 & $4269.7^{* * *}$ & $1788.6^{* * *}$ \\
\hline EE & 0.0264 & 0.0187 & 0.0233 & 2.0395 & 8.0306 & $1508.3^{* * *}$ & $3815.8^{* * *}$ \\
\hline AEH & 0.0129 & 0.0053 & 0.0200 & 4.3337 & 32.998 & $35060^{* * *}$ & $4837.6^{* * *}$ \\
\hline BBP & 0.0304 & 0.0164 & 0.0407 & 4.0109 & 26.726 & $22557^{* * *}$ & $4185.4^{* * *}$ \\
\hline GDYW & 0.0374 & 0.0268 & 0.0312 & 2.0249 & 8.0401 & $1503.2^{* * *}$ & $2770.3^{* * *}$ \\
\hline GAMC & 0.0371 & 0.0243 & 0.0389 & 3.1929 & 18.480 & $10083^{* * *}$ & $4493.5^{* * *}$ \\
\hline BEE & 0.0172 & 0.0116 & 0.0172 & 2.5172 & 11.479 & $3496.6^{* * *}$ & $3329.2^{* * *}$ \\
\hline SRA. & 0.0292 & 0.0168 & 0.0367 & 3.6916 & 23.178 & $16600^{* * *}$ & $3620.7^{* * *}$ \\
\hline
\end{tabular}

Notes: LMT, JXML, EE, AEH, BBP, GDYW, GAMC, BEE, and SRA represent Lepu Medical Technology, Jiangsu Xinning Modern Logistics, Eve Energy, Aier Eye Hospital, Beijing Beilu Pharmaceutical, Gansu Da Yu Water-saving, Gifore Agricultural Machinery Chain, Bode Energy Equipment, and Siasun Robot \& Automation, respectively.

${ }^{* * *}$ indicate significance at the $10 \%, 5 \%$, and $1 \%$ levels, respectively.

report our estimation results. The $\operatorname{AR}(1)-\mathrm{GARCH}(1,1)$ specifications are suitable for stock returns and the $\operatorname{AR}(2)-\operatorname{GARCH}(1,1)$ specifications are suitable for trading volume. All coefficients of the GARCH term $(\beta)$ with values less than one are statistically significant at the $1 \%$ level. Further, the $t$ distribution is justified at the $1 \%$ significance level, suggesting that the tails of the error terms are heavy compared with the normal distribution, and that the $\mathrm{ARCH}$ effects exist.
Tables 3 and 4 also show that the $Q(s)$ and $Q^{2}(s)$ statistics validate the empirical results of the ARGARCH models. The $Q(s)$ statistic at lag $s$ is a test statistic that follows an asymptotical distribution with degrees of freedom equal to the number of autocorrelations less the number of parameters. Its null hypothesis assumes that there is no autocorrelation up to lag $s$ for standardized residuals. The $Q^{2}(s)$ statistic at lag $s$ proposes a null hypothesis of no autocorrelation up to order $s$ for standardized squared residuals.

Table 3: Estimation Results of Marginal Distribution for Returns

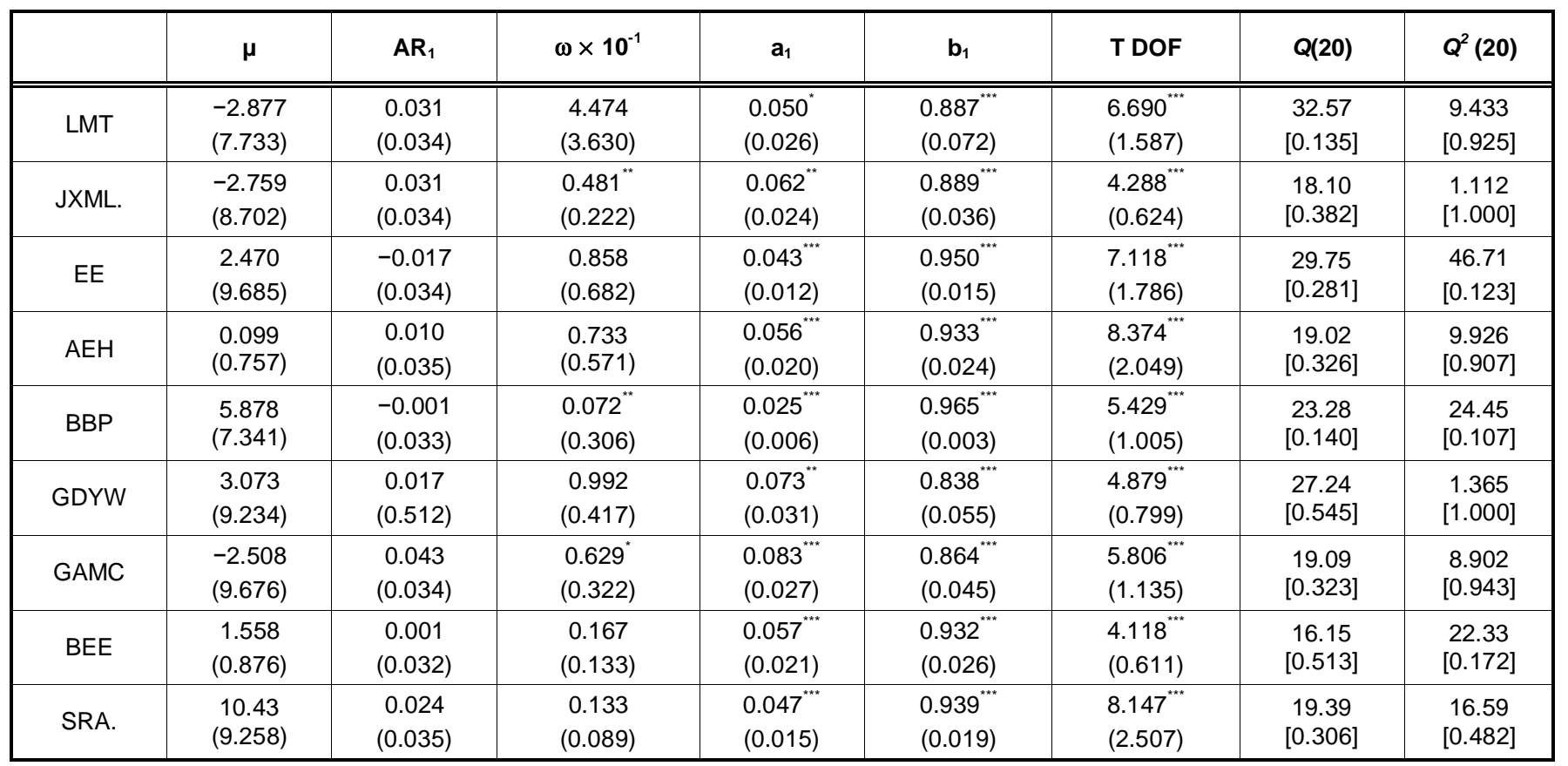

Notes: LMT, JXML, EE, AEH, BBP, GDYW, GAMC, BEE, and SRA represent Lepu Medical Technology, Jiangsu Xinning Modern Logistics, Eve Energy, Aier Eye Hospital, Beijing Beilu Pharmaceutical, Gansu Da Yu Water-saving, Gifore Agricultural Machinery Chain, Bode Energy Equipment, and Siasun Robot \& Automation, respectively. The numbers in square brackets are $p$-values. $Q(20)$ and $Q^{2}(20)$ are the Ljung-Box $Q$ statistics for the null hypothesis of no autocorrelation up to order 20 for standardized residuals (standardized squared residuals). ${ }^{*},{ }^{\star *}$, and ${ }^{* \star *}$ indicate significance at the $10 \%, 5 \%$, and $1 \%$ levels, respectively. 
Table 4: Estimation Results of Marginal Distribution for Volumes

\begin{tabular}{|c|c|c|c|c|c|c|c|c|c|}
\hline & $\mu \times 10^{-1}$ & $A R_{1}$ & $\mathbf{A R} \mathbf{R}_{2}$ & $\omega$ & $a_{1}$ & $b_{1}$ & T DOF & $Q(20)$ & $Q^{2}(20)$ \\
\hline LMT & $\begin{array}{l}-2.309 \\
(1.479)\end{array}$ & $\begin{array}{c}-0.327^{* * *} \\
(0.031)\end{array}$ & $\begin{array}{l}-0.261^{* \star \star} \\
(0.031)\end{array}$ & $\begin{array}{l}0.905^{\star \star *} \\
(0.128)\end{array}$ & $\begin{array}{c}0.021 \\
(0.031)\end{array}$ & $\begin{array}{l}0.526^{* \star \star} \\
(0.068)\end{array}$ & $\begin{array}{l}8.213^{\star \star \star} \\
(2.039)\end{array}$ & $42.25[0.616]$ & $10.32[0.889]$ \\
\hline JXML. & $\begin{array}{l}-4.603^{* * *} \\
(1.479)\end{array}$ & $\begin{array}{c}-0.257^{* * *} \\
(0.028)\end{array}$ & $\begin{array}{l}-0.149^{* * *} \\
(0.027)\end{array}$ & $\begin{array}{l}2.158^{\star \star *} \\
(4.772)\end{array}$ & $\begin{array}{c}0.098 \\
(0.055)\end{array}$ & $\begin{array}{l}0.822^{* * *} \\
(0.195)\end{array}$ & $\begin{array}{l}5.760^{* * *} \\
(1.050)\end{array}$ & $36.19[0.431]$ & $17.21[0.439]$ \\
\hline EE & $\begin{array}{l}-2.681^{\star *} \\
(1.298)\end{array}$ & $\begin{array}{c}-0.364^{\star * *} \\
(0.031)\end{array}$ & $\begin{array}{l}-0.220^{* * *} \\
(0.032)\end{array}$ & $\begin{array}{c}71.85 \\
(80.68)\end{array}$ & $\begin{array}{c}0.013 \\
(0.012)\end{array}$ & $\begin{array}{l}0.945^{* * *} \\
(0.053)\end{array}$ & $\begin{array}{l}7.404^{* * *} \\
(1.702)\end{array}$ & $63.32[0.121]$ & 20.69 [0.241] \\
\hline $\mathrm{AEH}$ & $\begin{array}{l}-1.785 \\
(1.438)\end{array}$ & $\begin{array}{c}-0.485^{* \star *} \\
(0.033)\end{array}$ & $\begin{array}{l}-0.205^{\star \star \star} \\
(0.029)\end{array}$ & $\begin{array}{c}58.58 \\
(36.33)\end{array}$ & $\begin{array}{l}0.072^{* *} \\
(0.035)\end{array}$ & $\begin{array}{l}0.609^{* * *} \\
(0.213)\end{array}$ & $\begin{array}{l}10.97^{* \star *} \\
(3.419)\end{array}$ & $67.72[0.106]$ & $11.32[0.839]$ \\
\hline BBP & $\begin{array}{l}-1.553 \\
(1.576) \\
\end{array}$ & $\begin{array}{c}-0.313^{* * *} \\
(0.032)\end{array}$ & $\begin{array}{l}-0.149^{* * *} \\
(0.032)\end{array}$ & $\begin{array}{l}24.93^{* * *} \\
(21.18)\end{array}$ & $\begin{array}{l}0.018 \text { ** } \\
(0.009)\end{array}$ & $\begin{array}{l}0.969^{* * *} \\
(0.017)\end{array}$ & $\begin{array}{l}13.68^{* * *} \\
(5.511)\end{array}$ & $45.32[0.218]$ & $13.21[0.729]$ \\
\hline GDYW & $\begin{array}{l}-1.922 \\
(1.467)\end{array}$ & $\begin{array}{c}-0.240 * * \\
(0.033)\end{array}$ & $\begin{array}{c}-0.159^{\star * *} \\
(0.034)\end{array}$ & $\begin{array}{l}79.61^{* * *} \\
(103.5)\end{array}$ & $\begin{array}{c}0.024 \\
(0.031)\end{array}$ & $\begin{array}{l}0.495^{\star * *} \\
(0.028)\end{array}$ & $\begin{array}{l}11.73^{* * *} \\
(4.157)\end{array}$ & $41.94[0.638]$ & $15.78[0.538]$ \\
\hline GAMC & $\begin{array}{c}-3.783^{\star \star \star} \\
(0.129)\end{array}$ & $\begin{array}{c}-0.301^{\star \star *} \\
(0.002)\end{array}$ & $\begin{array}{c}-0.228^{\star * \star} \\
(0.002)\end{array}$ & $\begin{array}{l}25.06^{\star \star \star} \\
(5.982)\end{array}$ & $\begin{array}{l}0.067^{* \star *} \\
(0.001)\end{array}$ & $\begin{array}{l}0.432^{\star \star *} \\
(0.005)\end{array}$ & $\begin{array}{l}6.838^{* * *} \\
(0.267)\end{array}$ & $53.34[0.130]$ & $9.467[0.924]$ \\
\hline BEE & $\begin{array}{l}-3.495^{* *} \\
(1.436)\end{array}$ & $\begin{array}{c}-0.315^{* * *} \\
(0.031)\end{array}$ & $\begin{array}{c}-0.207^{* * *} \\
(0.031)\end{array}$ & $\begin{array}{c}39.15 \\
(64.73)\end{array}$ & $\begin{array}{c}0.009 \\
(0.014)\end{array}$ & $\begin{array}{l}0.819^{* * *} \\
(0.314)\end{array}$ & $\begin{array}{l}5.801^{* * *} \\
(0.983)\end{array}$ & $32.45[0.142]$ & $23.53[0.132]$ \\
\hline SRA. & $\begin{array}{l}-2.173^{*} \\
(1.262)\end{array}$ & $\begin{array}{c}-0.457^{4 * t} \\
(0.031)\end{array}$ & $\begin{array}{c}-0.230 \\
(0.029)\end{array}$ & $\begin{array}{c}43.60 \\
(27.94)\end{array}$ & $\begin{array}{c}0.023^{*} \\
(0.014)\end{array}$ & $\begin{array}{l}0.725^{* * *} \\
(0.187)\end{array}$ & $\begin{array}{l}10.72^{\text {t*t }} \\
(3.346)\end{array}$ & $54.63[0.852]$ & $48.08[0.831]$ \\
\hline
\end{tabular}

Notes: LMT, JXML, EE, AEH, BBP, GDYW, GAMC, BEE and SRA represents Lepu Medical Technology, Jiangsu Xinning Modern Logistics, Eve Energy, Aier Eye Hospital, Beijing Beilu Pharmaceutical, Gansu Da Yu Water-saving, Gifore Agricultural Machinery Chain, Bode Energy Equipment, and Siasun Robot \& Automation, respectively. The numbers in square brackets are $p$-values. $Q(20)$ and $Q^{2}(20)$ are the Ljung-Box $Q$ statistics for the null hypothesis of no autocorrelation up to order 20 for standardized residuals (standardized squared residuals). ${ }^{*},{ }^{* *}$, and ${ }^{* * *}$ indicate significance at the $10 \%, 5 \%$, and $1 \%$ levels, respectively.

According to Tables $\mathbf{3}$ and $\mathbf{4}$, the null hypothesis of no autocorrelation up to order 20 for standardized residuals and standardized squared residuals is accepted for all countries, supporting our model specifications. Overall, the results are acceptable and sufficient to describe the marginal behavior of trading volume and stock returns.

\subsection{DECO Specifications}

The second step is to estimate the DECO model based on the conditional variance from step one.
Figure 1 illustrates the DECOs of trading volume and stock returns. Table $\mathbf{5}$ shows the results of the DECO model for both trading volume and stock returns.

Table 5 shows that the sum of $a$ and $b$ is less than one for all cases, indicating that the DECO parameters are in the range of typical estimates from the $\mathrm{GARCH}$ model. Further, rounded to three decimal places, the sum of $a$ and $b$ rounds to one in the case of trading volume, suggesting that the equicorrelation is almost integrated, which is consistent with the contribution of Carroll and Keamey (2012). In the case of stock

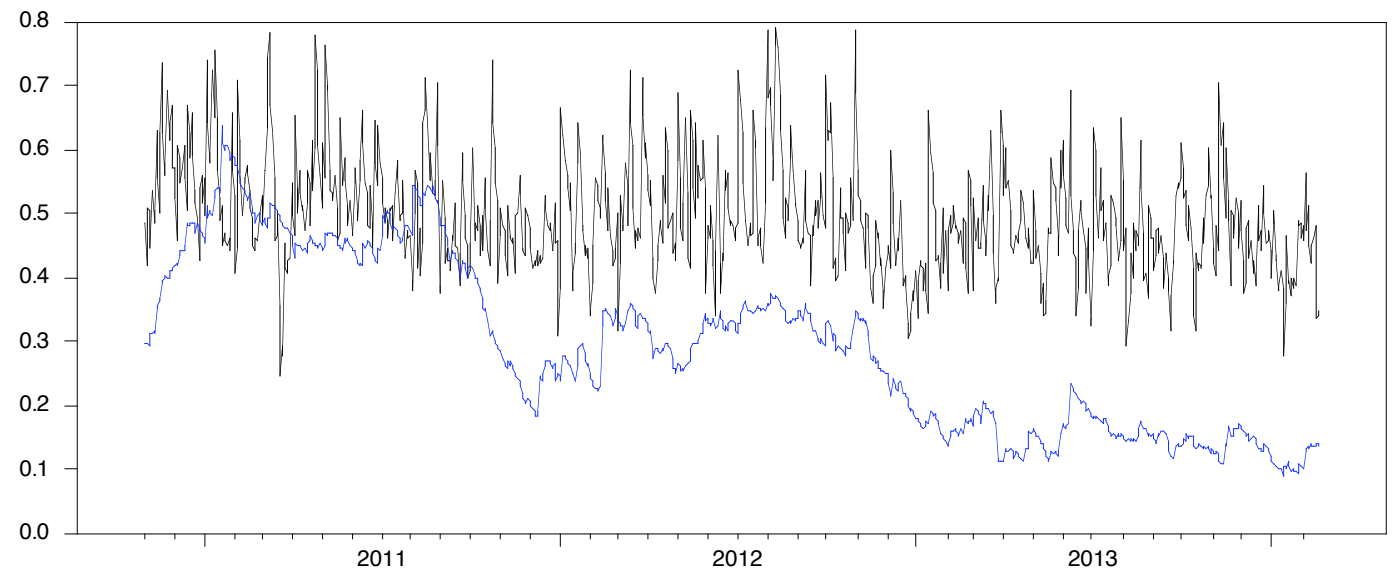

Figure 1: DECOs for returns (black) and volume (blue). 
Table 5: Estimation Results of DECOs

\begin{tabular}{|c|c|c|c|}
\hline & $\boldsymbol{a}$ & $\boldsymbol{b}$ & Log Likelihood $^{*}$ \\
\hline \hline Returns & $0.199(0.019)^{* * *}$ & $0.494(0.035)^{* * *}$ & -9517.4 \\
\hline Volumes & $0.026(0.006)^{* * *}$ & $0.971(0.008)^{\ldots *}$ & -10251 \\
\hline
\end{tabular}

Notes: The numbers given in parentheses are standard errors. ${ }^{* * *}$ means statistical insignificance at the $1 \%$ level. The restriction condition is $a+b<1$.

returns, the degree of integration is less than that of trading volume, indicating that stock returns perform more independently than trading volume. As shown in Figure 1, we can see that the DECO of trading volume decreases with time, whereas the DECO of stock returns does not. The reason for this is that the stock of the GEM is the hot issue at the initial time because only 28 companies meet the requirements for their IPOs. With the development of the GEM, the number of listed companies increases to disperse the funds, which eases the imbalance between demand and supply. Figure 1 illustrates that the hot issue effect disappears within two years of the IPO. Guo et al. (2010) note that the IPO cycles exist in the China A-share market. The hot issue effect will disappear within two years after the firms are listed in the China GEM. In other words, the rational learning process requires almost two years for most investors.

To examine the relationship between trading volume and stock returns in the GEM, we employ Spearman's correlation coefficient $(\rho=0.362, p<0.001)$ and Pearson's correlation coefficient $(\rho=0.348$, $p<0.001)$. Both statistics indicate a positive significant relationship between the DECO of stock returns and the DECO of trading volumes. The trading volume still plays an important role in determining the stock price during the process of price discovery. Consistent with previous studies, Campbell et al. (1993) and Carroll and Keamey (2012) find that the trading volume does explain stock returns. With GEM expansion, we witness market efficiency improvements.

\section{CONCLUSION}

This paper investigates how long the hot issue effect persists, and examines the relationship between trading volume and stock returns in the China GEM. Using daily data of listed companies in the China GEM, we estimate the dynamic equicorrelation for both trading volumes and stock returns.

With respect to general correlation, we find that returns and volumes are positively correlated at the $1 \%$ significance level. The interpretation for the result is intuitive. The trading volume still plays a significant role in determining the stock price during the process of price discovery, which is consistent with the contribution of Griffin et al. (2007). The results indicate that the market works more efficiently with GEM expansion.

Further, by illustrating the dynamic equicorrelation for both returns and volumes, we find that the imbalance between demand and supply for GEM stock has been relieved because the DECO volume decreased around 2011. This result indicates that the hot issue effect disappears within two years post-IPO. In other words, the rational learning process requires almost two years for most investors.

Our findings also suggest that the GEM works efficiently if the Chinese authorities solve the problem of financing growth enterprises through market strategies. There is evidence to suggest that the information content of trading volume can forecast stock returns.

\section{ACKNOWLEDGEMENT}

We are grateful to an anonymous referee foe helpful comments and suggestions. The research performed by the third author is in part supported by the Grant-inAid of the Japan Society for the Promotion of Science.

\section{REFERENCES}

Aboura, S., Chevallier, J. (2014) Volatility equicorrelation: a crossmarket perspective. Economic Letters 122, 289-295. http://dx.doi.org/10.1016/j.econlet.2013.12.008

Andersen, T. (1996) Return volatility and trading volume: an information flow interpretation of stochastic volatility. Journal of Finance 51, 169-204. http://dx.doi.org/10.1111/j.1540-6261.1996.tb05206.x

Brailsford, T., Heaney, R., Powell, J., Shi, J. (2000). Hot and cold IPO markets: identification using a regime switching model. Multinational Finance Journal 4, 35-68.

Bollerslev, T. (1987) A conditional heteroskedastic time series model for speculative prices and rates or return. The Review of Economics \& Statistics 69, 542-547. http://dx.doi.org/10.2307/1925546

Campbell J.Y., Grossman, S.J., Wang, J. (1993) Trading volume and serial correlation in stock returns. Quarterly Journal of Economics 108, 905-939. http://dx.doi.org/10.2307/2118454 
Carroll, T., Keamey, C. (2012) Do trading volumes explain the persistence of GARCH effects? Applied Financial Economics 22, 1993-2008. http://dx.doi.org/10.1080/09603107.2012.692871

Chen, S.S. (2012) Revisiting the empirical linkages between stock returns and trading volume. Journal of Banking \& Finance $36,1781-1788$. http://dx.doi.org/10.1016/j.jbankfin.2012.02.003

Engle, R. (1982) Autoregressive conditional heteroskedastic models with estimates of the variance of inflation in the United Kingdom inflation. Econometrica 50, 987-1007. http://dx.doi.org/10.2307/1912773

Engle, R. (2002). Dynamic conditional correlation: a simple class of multivariate generalized autoregressive conditional heteroskedasticity models. Journal of Business \& Economic Statistics 20, 339-350. http://dx.doi.org/10.1198/073500102288618487

Engle, R., Kelly, B. (2012) Dynamic Equicorrelation. Journal of Business \& Economic Statistics 30, 212-228. http://dx.doi.org/10.1080/07350015.2011.652048

Girard, E., Biswa, R. (2007) Trading volume and market volatility: developed versus emerging stock markets. The Financial Review 42, 429-459. http://dx.doi.org/10.1111/j.1540-6288.2007.00178.x

Guo, H., Brooks, R., Shami, R. (2010) International Review of Economics and Finance 19, 196-210. http://dx.doi.org/10.1016/j.iref.2009.10.002

Griffin, J.M., Nardari, F., Stulz, R.M. (2007) Do investors trade more when stocks have performed well? Evidence from 46 countries. Review of Financial Studies 20, 905-951. http://dx.doi.org/10.1093/rfs/hhl019

Hutson, E., Kearney, C., Lynch, M. (2008) Volume and skewness in international equity markets. Journal of Banking \& Finance $32,1255-1268$ http://dx.doi.org/10.1016/j.jbankfin.2007.10.011

Ibbotson, R., Jaffe, F. (1975) "Hot issue"markets. Journal of Finance 30, 1027-1042.
Karpoff, J.M. (1987) The relation between price changes and trading volume: a survey. Journal of Financial \& Quantitative Analysis 22, 109-126. http://dx.doi.org/10.2307/2330874

Lee, B.S., Rui, O.M. (2002) The dynamic relationship between stock returns and trading volume: domestic and cross-country evidence. Journal of Banking \& Finance 26, 51-78. http://dx.doi.org/10.1016/S0378-4266(00)00173-4

$\mathrm{Li}$, J., Wu, C. (2006) Daily return volatility, bid-ask spreads and information flow: analyzing the information content of volume. Journal of Business 79, 2697-2739. http://dx.doi.org/10.1086/505249

Lin, S., Wang, S., Tsai, P. (2009). Application of hidden Markov switching moving average model in the stock markets: theory and empirical evidence. International Review of Economics and Finance 18, 306-317. http://dx.doi.org/10.1016/j.iref.2008.06.010

Lowry, M. (2003). Why does IPO volume fluctuate so much? Journal of Financial Economics 67, 3-40. http://dx.doi.org/10.1016/S0304-405X(02)00230-1

Ning, C., Wirjanto, T.S. (2009). Extreme return-volume dependence in east-Asian stock markets: a copula approach. Finance Research Letters 6, 202-209. http://dx.doi.org/10.1016/j.frl.2009.09.002

Statman, M., Thorley, S., Vorkink, K. (2006) Investor overconfidence and trading volume. Review of Financial Studies 19, 1531. 1565. http://dx.doi.org/10.1093/rfs/hhj032

Ritter, J. (1984). The"hot issue"market of 1980. Journal of Business 57, 215-240. http://dx.doi.org/10.1086/296260

Yilmaz, M.K., Sensoy, A., Ozturk, K., Hacihasanoglu, E. (2015) Cross-sectoral interactions in Islamic equity markets. PacificBasin Finance Journal, Forthcoming. http://dx.doi.org/10.1016/.jpacfin.2014.12.008

Verbeek, M. (2004) A Guide to Modern Econometrics. 2nd version, John Wiley \& Sons Ltd, England.

Received on 16-01-2015

Accepted on 12-02-2015

Published on 27-02-2015

DOI: http://dx.doi.org/10.6000/1929-7092.2015.04.04

(c) 2015 Yang et al.; Licensee Lifescience Global.

This is an open access article licensed under the terms of the Creative Commons Attribution Non-Commercial License (http://creativecommons.org/licenses/by-nc/3.0/) which permits unrestricted, non-commercial use, distribution and reproduction in any medium, provided the work is properly cited. 